\title{
Exploring the concept of optimal functionality in old age
}

This article was published in the following Dove Press journal:

Journal of Multidisciplinary Healthcare

31 January 2014

Number of times this article has been viewed

\author{
Samal Algilani,** \\ Lina Östlund-Lagerström ${ }^{1,2, *}$ \\ Annica Kihlgren' \\ Karin Blomberg' \\ Robert J Brummer ${ }^{1,2}$ \\ Ida Schoultz ${ }^{1,2}$ \\ 'Nutrition and Physical Activity \\ Research Centre, ${ }^{2}$ Nutrition Gut \\ Brain Interactions Research Centre, \\ School of Health and Medicine, \\ Faculty of Medicine and Health, \\ Örebro University, Örebro, Sweden \\ *These authors contributed equally \\ to this work
}

Background: Aging is characterized by loss of function and represents a perspective that puts the focus on the negative aspects of aging. Thus, it is fundamental to shift the focus from loss of function to maintaining good health and personal satisfaction through life; in other words, to promote optimal functionality at a level appropriate for older adults. However, it is not yet known what constitutes optimal functionality from the older adult's own perspective.

Objective: To explore the concept of optimal functionality in old age from the older adult's perspective (ie, people over 65 years of age) in industrialized Western countries.

Methods: We undertook a scoping review and searched two electronic databases (PubMed and the Cumulative Index to Nursing and Allied Health Literature [CINAHL]) from January 2002 to July 2013 for scientific studies, using the key search term personal satisfaction. In total, 25 scientific studies were analyzed.

Results: Only six of the included articles applied a qualitative methodology. By analyzing the results of these articles, three major themes were identified as cornerstones in the concept of optimal functionality at old age: 1) self-related factors (eg, mental well-being); 2) body-related factors (eg, physical well-being); and 3) external factors equal to demographic and environmental factors.

Conclusion: There is a lack of qualitative studies in the current literature, and hence of what constitutes optimal functionality from the older adult's perspective. The results outlined in this review identify three cornerstones (self-related factors, body-related factors, and external factors) of what constitutes optimal functionality at old age. However, it is vital that these findings are taken further and are evaluated through qualitative studies to reflect older adults' opinions.

Keywords: optimal functionality, aging, personal satisfaction

\section{Introduction}

The development of the Western world and, in particular, the technical revolution has led to a better living standard, promoting greater life expectancy. The proportion of citizens in the Western world reaching old age is increasing at an alarmingly high rate, and is estimated to soon outnumber young children. ${ }^{1}$

Aging is characterized by loss of function (ie, a decreased ability to carry out everyday activities) and represents a perspective that puts the negative aspects of aging in focus. This is supported by the health belief model, initially introduced by Rosenstock et al, which postulates that an individual's beliefs and opinion about a certain disease will affect their behavior and the handling of the situation..$^{2-4}$ Thus, defining aging by loss of function will incorporate negative beliefs into the older person's own opinion of what constitutes aging, instead of focusing on the possibility of maintaining mental
Correspondence: Ida Schoultz

Department of Medicine and Health Sciences, Nutrition Gut Brain Interactions Research Centre, Fakultetsgatan I, Örebro University, 70I 82 Örebro, Sweden

Tel +4619303209

Email ida.schoultz@oru.se 
and physical well-being through life. ${ }^{5,6}$ Hence, it is important to shift the focus from loss of function toward maintaining good health and well-being in order to function optimally at the older adult's individual level.

To date, numerous scientific articles have elucidated the relationship between aging and specific functions, like cognitive and physical function. ${ }^{7-10}$ Despite the substantial body of research in this field, little is known about how the older adult defines optimal functionality and what he or she states as necessary factors and functions to experience personal satisfaction on an individual level.

We conducted a scoping review of the current literature with the guiding question: what factors and functions constitute optimal functionality from the older adult's perspective? Our aim was to identify the core of the concept of optimal functionality in old age.

Increased knowledge of what constitutes optimal functionality will also lead to a model applicable to the care of older adults and will function as an initial tool to help the caregivers and medical staff identify what constitutes optimal functionality for their patients on an individual level.

\section{Methods}

We adopted a scoping review approach using the methodology originally described by Arksey and O'Malley in 2005. ${ }^{11}$ This approach is an iterative process whereby existing literature is identified, examined, and conceptually mapped, and where gaps in the research field are recognized. ${ }^{12}$ Arksey and O'Malley identified five stages to be followed when conducting a scoping review: 1) the identification of a research question; 2) finding the relevant studies; 3) the selection of studies to be included in the review; 4) data extraction from the included studies; 5) assembling, summarizing, and reporting the results of the review; and the optional stage, 6) consultation. ${ }^{11}$

\section{Data sources and search strategy}

Electronic literature databases including PubMed (US National Library of Medicine, Bethesda, MD, USA) and Cumulative Index to Nursing and Allied Health Literature (CINAHL) were searched using a comprehensive search strategy designed with the assistance of a librarian experienced in conducting advanced literature searches, including systematic reviews. The date range was set from January 2002-July 2013 to reflect the current research performed during a 10 -year period. New articles published during 2012-2013 were also included in order to incorporate the most recent research in the field. The key search term was first set to (optimal functionality) AND (elderly OR older adults OR old age OR old persons). However, this term only retrieved articles focusing on physical functionality and did not generate relevant articles to define the concept of optimal functionality in a holistic perspective. The search term was not truncated to optimal function, as the aim was to understand optimal functionality among older adults in a broad perspective and not to focus on the fulfillment of one or a few particular functions.

In order to generate a search term suitable for our aim and in close conjunction with the concept of optimal functionality, we performed focus group discussions (FGDs) among older adults in order to find factors important for mental and physical well-being identified by the participants themselves. FGDs were chosen as this data collection method aims to facilitate individuals' exploration and clarification of their views through group interaction in a manner not possible in one-on-one interviews. Each FGD was led by an experienced moderator (authors $\mathrm{AK}$ and $\mathrm{KB}$ ) and followed the procedures for FGDs. ${ }^{13}$ Topics addressed in the FGDs were about the participants' perspectives on health/illness and maintaining health. Each FGD was audio-recorded with the participants' permission and lasted 60-90 minutes. All interviews were transcribed verbatim. A total of 15 people participated in two FGDs, with seven or eight persons in each (mean age: 82.9; range 67-93). The participants were residents of two senior living homes in the municipality of Örebro, Sweden. The senior living homes included in this study represented apartments functioning as individual homes for the older adults with minor adjustments (such as accessible bathrooms) to facilitate everyday life, as well as common rooms to stimulate activities and conversation. In addition, the two senior living homes also had a food service, as well as a manager, which gave extra support to the residents. In both groups, the feeling of being satisfied with one's life came up as an important factor for maintaining both physical and mental well-being. It was clear that experiencing personal satisfaction served as an important foundation in an older adult's life, facilitating an active life both on a physical and social level, and leading to a feeling of a healthier and happier life. We therefore set the final key search term to (personal satisfaction) and (elderly OR older adults OR old age OR old persons) as it reflects a factor important for mental and physical well-being identified by the older adults themselves. Furthermore, personal satisfaction serves as a foundation for optimal functionality as you cannot function optimally in a holistic perspective without experiencing personal satisfaction. 


\section{Inclusion and exclusion criteria}

In the search process, limitations were set to English language studies only. Inclusion criteria were: 1) complete peerreviewed full articles (not abstracts only or commentaries, letters, or editorials) reported in English; 2) full articles defining older adults as 65 years and older; and 3) full articles of scientific studies conducted in Western countries (including Australia and New Zealand). Articles were excluded if they were published as abstracts only or represented an intervention study.

\section{Selection of articles}

Two independent reviewers (authors SA and LÖL) examined the titles and abstracts identified in the literature search. Articles were selected if the inclusion criteria were met and if both reviewers considered the citation potentially relevant. Disagreement at any stage of study selection was resolved by discussion and consensus between the two reviewers. In case of disagreement, a third author was recruited to determine eligibility.

Each reviewer independently:

- assessed retrieved titles and abstracts for relevance and duplication;

- screened full text articles deemed eligible for inclusion;

- decided on including or excluding articles;

- extracted relevant data according to the method described below;

- appraised the quality of the included articles.

Our search identified and retrieved 2,454 articles from the two electronic databases searched (PubMed [US National Library of Medicine] and CINHAL). Following searching through the titles, 236 articles were included in the abstract search. Of these, 141 were excluded, 23 were identified as duplicates between the two databases, and the remaining articles were found not to meet the inclusion criteria. Subsequently, 95 articles were found eligible for full text screening. During this process, 70 articles were excluded as they did not meet the inclusion criteria, leaving a total 25 full text articles to be included in the analysis. ${ }^{14-38} \mathrm{~A}$ flow chart of the study selection process is outlined in Figure 1. Nineteen of the included articles represented quantitative studies, while six used a qualitative methodology. The quality of each article was evaluated by the impact factor of each journal where the article was published.

\section{Data analysis}

A spreadsheet was created to record the following items to generate an overview of the included articles: first author;

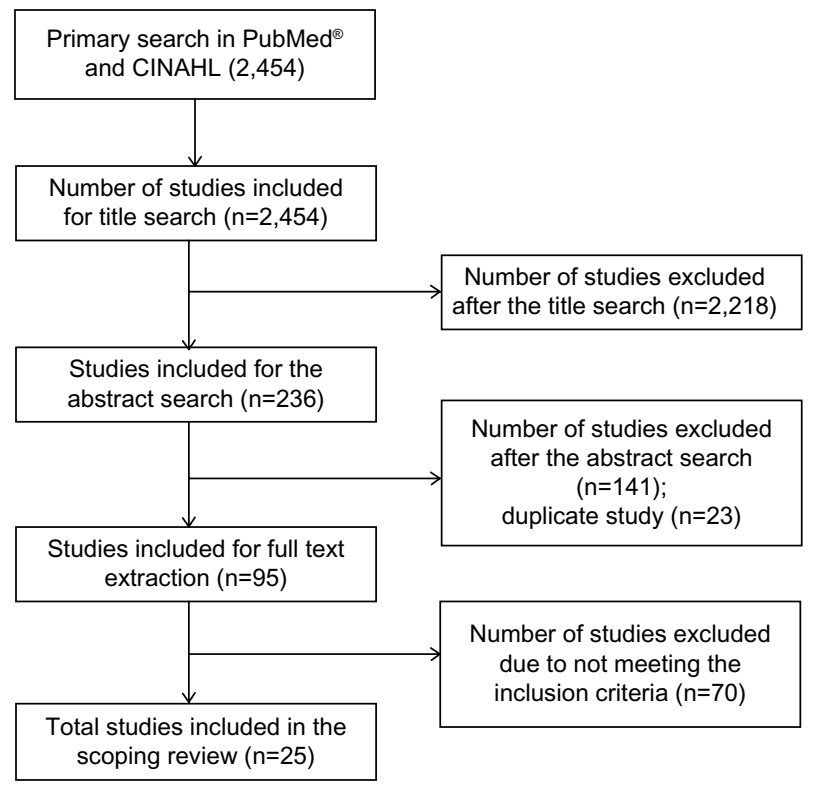

Figure I Overview of the study selection process.

Notes: In the primary search of the two electronic databases (PubMed ${ }^{\circledR}$ [US National Library of Medicine, Bethesda, MA, USA] and CINHAL) using the search term (personal satisfaction); 2,454 articles were identified and included in the title search. Of these, 236 articles were eligible and were included in the abstract search. This resulted in the exclusion of $14 \mathrm{I}$ articles, including 23 that were identified as duplicates between the two databases. Ninety five articles were entered into the fulltext extraction process; 70 of these were excluded as they did not meet the inclusion criteria, resulting in a total number of 25 articles included in the scoping review.

Abbreviation: CINAHL, Cumulative Index to Nursing and Allied Health Literature.

country; publication year; current impact factor (extracted from journal citation reports [Thomas-Reuters Corporation]); methodology (with a focus on qualitative or quantitative measures) sample size; minimal inclusion age of study population; and identified themes (Table 1). As a second step, the following data were extracted and placed in a separate spreadsheet: authors; aim; study methodology; and results.

To further assess the results in order to explore the concept of optimal functionality, we conducted a step by step process where: 1) factors (ie, terms related to the key search term personal satisfaction) were identified from the extracted results of each article. Two independent reviewers evaluated the identified factors, which included factors having a positive (eg, physiological well-being, physical activity, etc) and a negative correlation (eg, depression, loneliness, etc) to the search term personal satisfaction; 2) the identified factors were further found to belong to one of nine identified areas, so-called aspects, and were subsequently divided into mental, activity, autonomy, capability, social, adjustment, demographic, health, and environmental aspects; 3 ) to create an overview of the generated aspects, all co-authors met to evaluate the data and divide the nine aspects into larger themes. The division of the aspects was discussed until consensus was reached among 
Table I Descriptions of the study findings

\begin{tabular}{|c|c|c|c|c|c|c|c|}
\hline First author & Country & $\begin{array}{l}\text { Year of } \\
\text { publication }\end{array}$ & $\begin{array}{l}\text { Current } \\
\text { impact factor } \\
\text { of journal }\end{array}$ & Methodology & $\begin{array}{l}\text { Sample } \\
\text { size }\end{array}$ & $\begin{array}{l}\text { Minimal inclusion } \\
\text { age of study } \\
\text { population (years) }\end{array}$ & $\begin{array}{l}\text { Identified } \\
\text { themes }^{\text {b }}\end{array}$ \\
\hline Andersson ${ }^{29}$ & Sweden & 2008 & 2.075 & Qual & $\mathrm{N}=17$ & 78 & S, E \\
\hline Berg ${ }^{17}$ & Sweden & 2009 & 1.677 & Quant & $\mathrm{N}=453$ & 80 & $\mathrm{~S}, \mathrm{~B}, \mathrm{E}$ \\
\hline Berg $^{34}$ & Sweden & 2006 & 1.677 & Quant & $\mathrm{N}=315$ & 80 & $\mathrm{~S}, \mathrm{~B}, \mathrm{E}$ \\
\hline Bergland $^{28}$ & Norway & 2006 & 2.075 & Qual & $\mathrm{N}=26$ & 65 & $\mathrm{~S}, \mathrm{E}$ \\
\hline Bishop $^{25}$ & USA & 2006 & 1.677 & Quant & $\mathrm{N}=320$ & 65 & S, E \\
\hline Borg ${ }^{22}$ & Sweden & 2006 & 1.316 & Quant & $\mathrm{N}=522$ & 65 & $\mathrm{~S}, \mathrm{~B}, \mathrm{E}$ \\
\hline Chippendale ${ }^{23}$ & USA & 2013 & N/A & Quant & $\mathrm{N}=47$ & 65 & $\mathrm{E}$ \\
\hline Danhauer $^{27}$ & USA & 2006 & 0.464 & Quant & $\mathrm{N}=93$ & 65 & $\mathrm{~S}, \mathrm{~B}, \mathrm{E}$ \\
\hline Enkvist $^{19}$ & Sweden & 2012 & 1.717 & Quant & $N=68 I$ & 78 & S, B \\
\hline Enkvist $^{20}$ & Sweden & 2012 & 1.717 & Quant & $\mathrm{N}=68 \mathrm{I}$ & 78 & $B, E$ \\
\hline Golden ${ }^{15}$ & Ireland & 2011 & 1.677 & Quant/qual & $N=2,136$ & 65 & $\mathrm{~S}$ \\
\hline Golden ${ }^{16}$ & Ireland & 2009 & 2.977 & Quant & $\mathrm{N}=1,299$ & 65 & $\mathrm{~S}, \mathrm{~B}, \mathrm{E}$ \\
\hline Good $^{30}$ & New Zealand & 2008 & 0.68 & Qual & $\mathrm{N}=560$ & 65 & B \\
\hline Helvik $^{21}$ & Norway & 2011 & 1.966 & Quant & $N=10,958$ & 65 & $\mathrm{~S}, \mathrm{~B}, \mathrm{E}$ \\
\hline Jones ${ }^{24}$ & USA & 2003 & 1.678 & Quant & $\mathrm{N}=129$ & 65 & S, B, E \\
\hline Krause $^{37}$ & USA & 2007 & 3.089 & Quant/qual & $\mathrm{N}=605$ & 65 & $\mathrm{E}$ \\
\hline McKinley ${ }^{26}$ & USA & 2005 & 1.075 & Quant & $\mathrm{N}=21$ & 65 & S, E \\
\hline McLaughlin $^{36}$ & Australia & 2010 & 2.188 & Quant & $N=5,74 I$ & 72 & $\mathrm{E}$ \\
\hline Melendez $^{14}$ & Spain & 2009 & 1.717 & Quant & $N=18 \mid$ & 65 & S, B, E \\
\hline Ní Mhaoláin ${ }^{18}$ & Ireland & 2012 & 2.188 & Quant & $\mathrm{N}=466$ & 65 & S, B \\
\hline Nilsson ${ }^{38}$ & Sweden & 2011 & 1.717 & Quant & $\mathrm{N}=417$ & 75 & $\mathrm{E}$ \\
\hline Raske $^{32}$ & USA & 2010 & N/A & Qual & $\mathrm{N}=43$ & 65 & $\mathrm{~S}, \mathrm{~B}, \mathrm{E}$ \\
\hline Requena $^{35}$ & Spain & 2010 & 0.54 & Quant & $\mathrm{N}=310$ & 65 & $\mathrm{~S}, \mathrm{E}$ \\
\hline Stålbrand ${ }^{3 !}$ & Sweden & 2007 & 2.418 & Quant & $\mathrm{N}=212$ & 80 & B \\
\hline Sugiyama ${ }^{33}$ & UK & 2006 & N/A & Quant & $\mathrm{N}=53$ & 65 & $\mathrm{~B}, \mathrm{E}$ \\
\hline
\end{tabular}

Notes: a Methodology with focus on the use of quantitative or qualitative measures; bresentation of factors related to the identified themes in the results section of the included articles.

Abbreviations: B, body-related factors; E, external factors; N/A, not available; Qual, qualitative; Quant, quantitative; S, self-related factors.

the authors. Subsequently, the nine aspects were divided into three larger themes, where mental, capability, and adjustment aspects fell under the major theme self-related factors and autonomy; health and activity aspects were categorized into the theme body-related factors; consequently, demographic, social, and environmental aspects were identified as belonging to the major theme of external factors. Thus, the theme self-related factors focuses on mental well-being; the theme body-related factors emphasizes physical well-being; while the theme external factors points out the importance of demographic and environmental factors. The process of identifying the major themes is shown in Figure 2. In order to evaluate if the specific themes were equally represented in the included articles, we assessed if the result section included factors belonging to one or more themes. The connection between the major themes was further analyzed by studying the total count of the identified factors related to the different themes in the result section of each article. For the theme self-related factors, for example, factors such as lower depression, worry, coping skills, and active adjustment were counted when appearing in the results section of each included article. This process generated a number equal to how often factors belonging to a certain theme were included as a result in the included articles.

\section{Results}

\section{Distribution of the identified themes}

The structure of the optimal functionality concept is outlined in Figure 3. This illustration shows the three identified themes accompanied by their respective aspects as classified by the positive and negative factors extracted from the result section of the included articles.

Further analysis of the appearance of the factors revealed that a higher number of articles, nine in total, presented factors related to all three themes in their result sections, as outlined in the Venn diagram in Figure 4. Thus, showing that these themes are intricately linked as they are identified and discussed together. To further elucidate the relationship between the identified themes, all factors, positive and negative, corresponding to the specific aspects and subsequently the themes were counted 


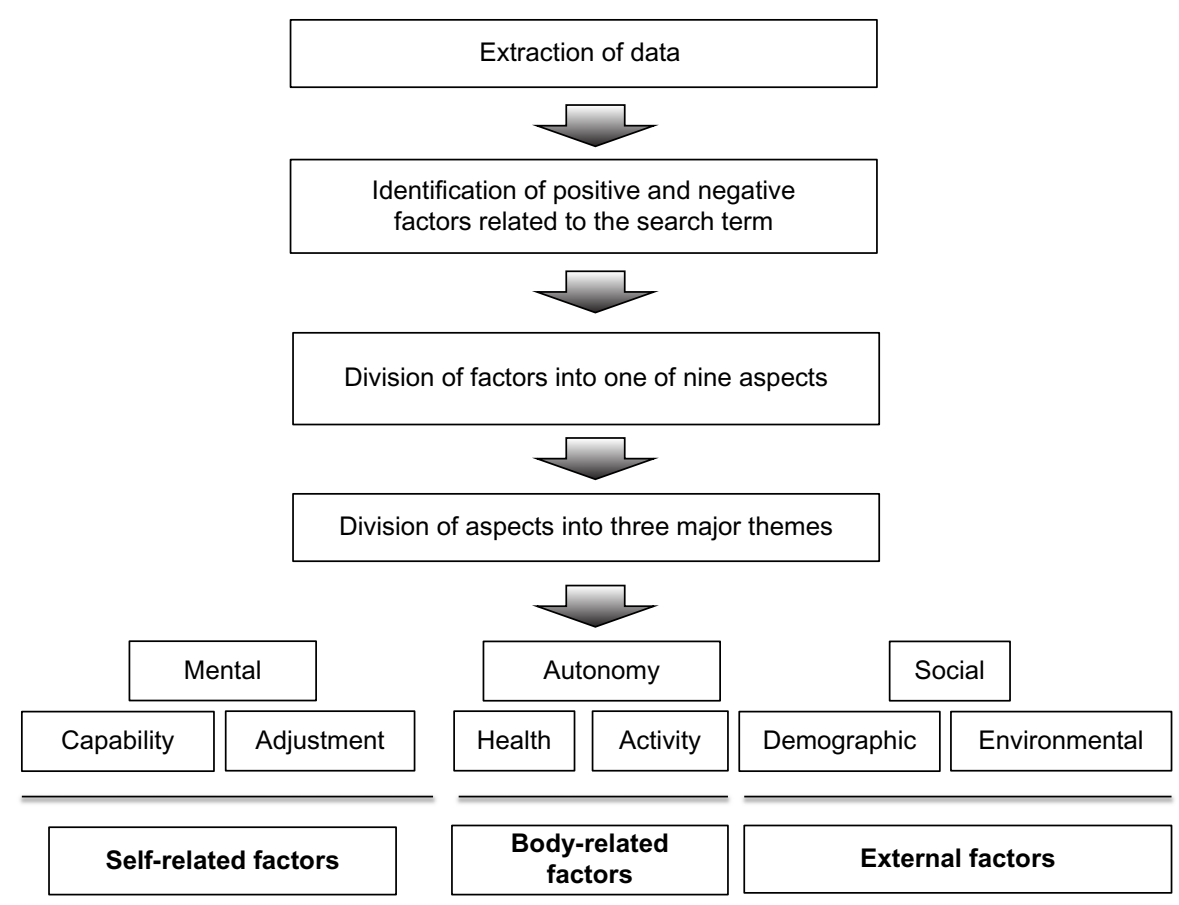

Figure 2 Overview of the analysis process.

Notes: Data important to answer the research question were extracted from the results section of the included articles. Positive (eg, psychological well-being) and negative factors (eg, loneliness, depression) related to the search term personal satisfaction were identified and further divided into nine aspects (Mental, Capability, Adjustment, Autonomy, Health, Activity, Social, Demographic, and Environmental). In a last step involving a discussion with all co-authors, the aspects were divided into three major themes, the cornerstones of optimal functionality at old age: self-related factors, body-related factors and environmental factors.

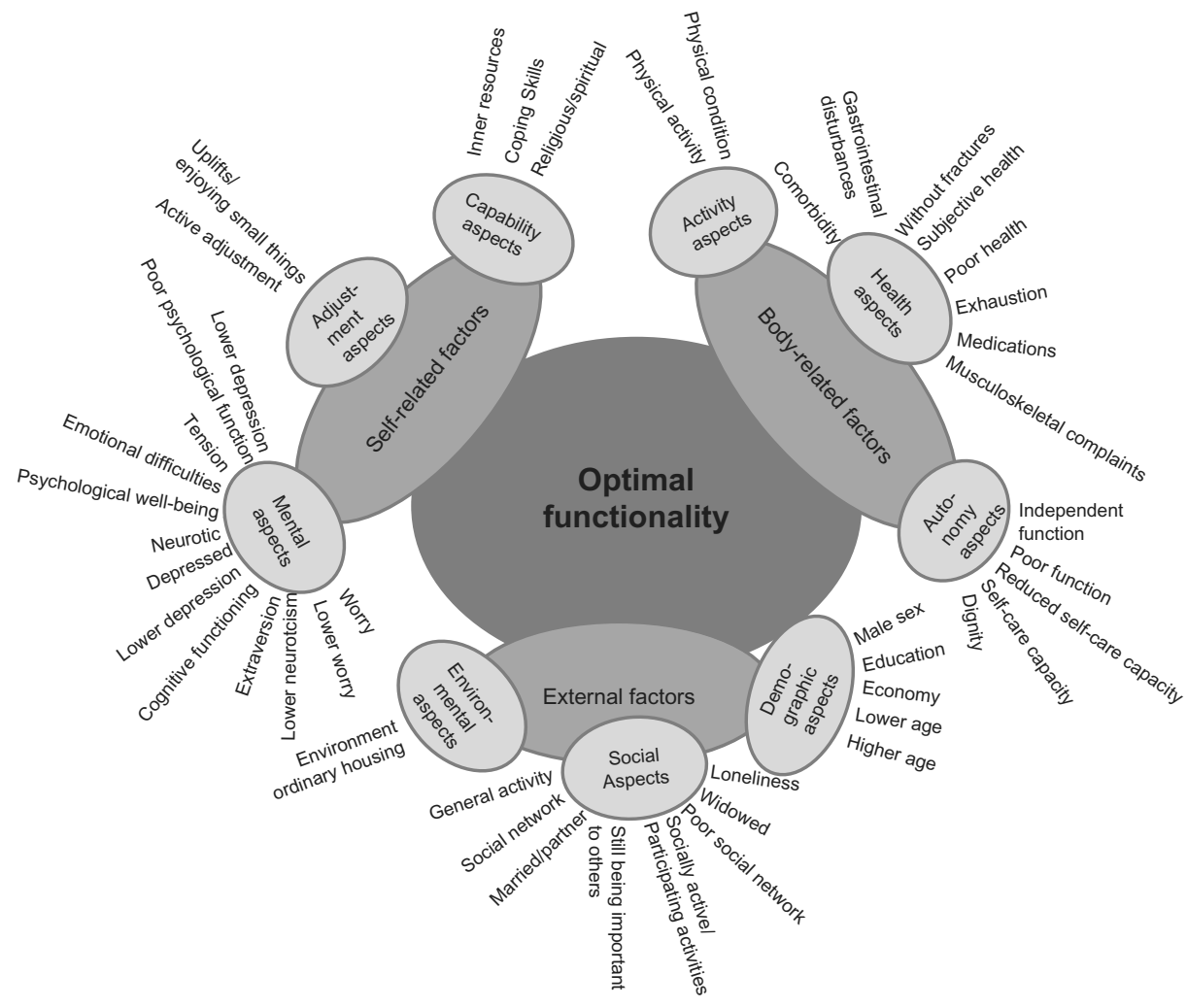

Figure 3 The structure of the concept of optimal functionality at old age.

Notes: Illustration of the identified positive and negative factors related to the search term personal satisfaction and their division into one of the nine aspects (Mental, Capability, Adjustment, Autonomy, Health, Activity, Social, Demographic, and Environmental) and subsequently the three major themes: self-related factors, body-related factors and external factors. Together these themes represent the concept of optimal functionality at old age. 


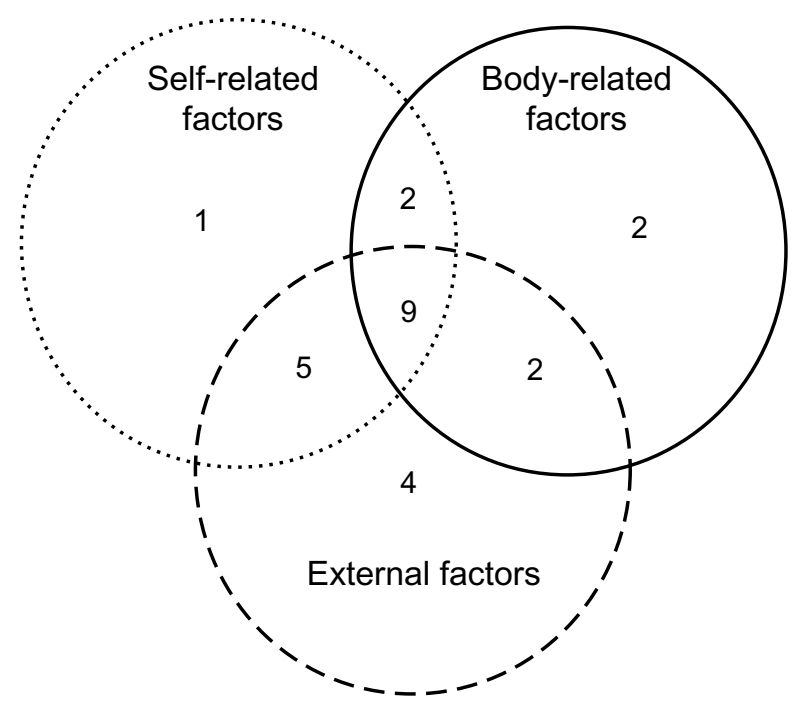

Figure 4 The distribution of the identified themes in the included articles. Notes: The Venn diagram illustrates the number of articles presenting factors related to one, two, or all three major themes in their result section. As shown in the figure, a higher number of articles (in total nine) were found to present factors related to all three themes.

when appearing in the results section of the included articles. This generated a number corresponding to the number of times a theme has been identified in the articles. As seen in Table 2, all themes were equally represented in the included articles. Factors related to the theme self-related factors were mentioned 33 times, factors related to body-related factors, were presented 35 times, while external factors had 46 quotations. Hence, this supports the theory that the themes are essential cornerstones and co-exist in the concept of optimal functionality.

\section{Mapping the major themes and their aspects \\ Self-related factors}

\section{Mental aspects}

Psychological well-being was identified as a major factor affecting personal satisfaction. ${ }^{14-21}$ In particular, lack of depression and fewer depressive symptoms were suggested to promote well-being and life satisfaction. ${ }^{17}$ This was confirmed in additional articles pointing out that life satisfaction

Table 2 The number of times factors related to the major themes are mentioned in the included articles

\begin{tabular}{ll}
\hline Major themes & $\begin{array}{l}\text { Number of times quoted } \\
\text { in the result section }\end{array}$ \\
\hline Self-related factors & 33 \\
Body-related factors & 35 \\
External factors & 46 \\
\hline
\end{tabular}

Note: ${ }^{a}$ Number illustrates how many times positive and negative factors related to the themes are mentioned in the results section of the included articles. is affected negatively if emotional difficulties and symptoms of tension and depression are present. ${ }^{19,20}$ Further, personality traits, like having an extroverted personality and lower levels of neuroticism, are positively correlated with life satisfaction. ${ }^{17,18}$ Absence of worry provides higher life satisfaction, whereas anxious experiences and feelings of worry negatively affect life satisfaction. ${ }^{22}$ Among older adults living in senior residences, feelings of being valued and important are a significant predictor to life satisfaction. ${ }^{23}$

\section{Capability aspects}

Having a problem-focused coping style, ie, an individual's ability to handle situations that are experienced as stressful or problematic, contributes to well-being. ${ }^{24}$ Likewise, past individual accomplishments through life and achievements related to individual resources contribute to happiness. ${ }^{25}$ Spirituality and religiosity also contribute to well-being in late adulthood. ${ }^{26,27}$

\section{Adjustment aspects}

Older adults who are willing to adjust and keep a positive mental attitude toward their current living conditions are more likely to thrive and to experience a good life..$^{28,29}$ Further, up-lifts, ie, enjoying small things and focusing on positive events, provides older adults with meaning and positive appreciation of one's life. ${ }^{27,29}$

These results indicate that good mental health together with a problem-focused coping style and the ability to adjust are essential for a good life in old age. A majority of the articles discuss the importance of depressive symptoms as related to poorer life satisfaction. Within the major theme self-related factors, the mental aspect came through as the main contributor to health and well-being.

\section{Body-related factors}

\section{Activity aspects}

To be physically active is of significant importance for experiencing higher life satisfaction. ${ }^{18,22,30}$ Apart from contributing to life satisfaction, maintained physical condition also contributes to good mental health. ${ }^{14}$

\section{Health aspects}

Comorbidity correlates negatively to life satisfaction. ${ }^{18,31}$ Specifically, gastrointestinal disturbances, musculoskeletal symptoms, and being afflicted with fractures have a negative effect on life satisfaction. Likewise, experiencing poor subjective health, having actual diseases, or being on medications all correlate to lower life satisfaction and poorer well-being. ${ }^{19,20,22,24,31,32}$ One 
of the reviewed articles also mentioned exhaustion as a key obstacle in reaching life satisfaction. ${ }^{18}$

\section{Autonomy aspects}

Independence in everyday life and functioning as "one would like" has a positive impact on quality of life and life satisfaction. ${ }^{19,22,30,32}$ Likewise, older people who report better functional capability are more satisfied with life. ${ }^{33}$ One paper, however, suggested only a moderate relationship between function at old age, when disease and disabilities are common parts of life, and life satisfaction. ${ }^{34}$ Moreover, maintaining dignity contributes to a good life. ${ }^{29}$

In summary, being active, not being afflicted with disease, and being independent in everyday life contributes to life satisfaction among old persons. Perceiving one's health as poor or actually having symptoms, such as gastrointestinal disturbances, both have a negative effect on life satisfaction. The results of this review also indicate the importance of maintaining dignity for a good life.

\section{External factors}

\section{Social aspects}

A social network is particularly important for older adult life satisfaction, which is clearly stated in several of the included articles. A well-established social network is defined by good quality and quantity of relations and frequent acquaintances. ${ }^{34-36}$ An individual who becomes increasingly satisfied with their social network also becomes more satisfied with life. ${ }^{17}$ Participating in social activities, such as meeting with friends, visiting cultural events, and doing accompanied gardening are described as important for life satisfaction. ${ }^{21,32}$ Receiving sufficient emotional support from family and friends as well as being important to others facilitates meaning in life and life satisfaction. ${ }^{26,29,37}$ In addition, isolation and loneliness is associated with lower life satisfaction. ${ }^{18,22}$ This is of importance since the likelihood of being alone increases with age. ${ }^{16}$

\section{Demographic aspects}

Chronological aging is associated with a slow decline in life satisfaction. ${ }^{14}$ However, it is generally accepted that older men show greater life satisfaction and well-being than older women. ${ }^{19,22,38}$ Further, marital status, such as being married, having a partner, or being widowed, is a predictor of life satisfaction, in the sense that sharing one's life with someone promotes life satisfaction, whereas being alone impacts life satisfaction negatively. ${ }^{17,18,34}$ Moreover, having a higher educational level is positively related to life satisfaction and subjective well-being, as is having a stable economic status. ${ }^{14,19,22,24}$

\section{Environmental aspects}

Living in a home-like environment and feeling at home brings life satisfaction and contributes to a good life. ${ }^{26,29}$ In particular, individuals living in ordinary housing show greater life satisfaction than nursing home residents, as do individuals living in supportive neighborhoods. ${ }^{22,33}$

The results of this literature review show that social relations and living environment contribute to life satisfaction. A social network, including family, friends, and acquaintances is of major importance for older adult well-being and satisfaction. Likewise, marital status, educational level, and financial stability are associated with a good life.

\section{Discussion}

We undertook a scoping review strategy in order to explore the concept of optimal functionality from older adults' perspectives. Our results demonstrate that the concept of optimal functionality is founded on three cornerstones: the identified major themes of self-related factors; body-related factors; and external factors. Our data compiles the present knowledge of what constitutes optimal functionality at old age. However, it is important to acknowledge that the aim of our study was to explore the concept from older adults' perspectives. As outlined in Table 1, it is evident that the majority of the articles included in the study were found to be quantitative (19), while only six were qualitative studies based on interviews. Hence, this illustrates a gap and lack of research focusing on what constitutes optimal functionality from the older adults' own perspectives. The lack of research is further supported by the observation that the search term (optimal functionality) AND (elderly OR older adults OR old age OR old persons) only retrieved articles focusing on physical functioning, leaving out the importance of mental well-being, as well as demographic and environmental factors. Together, these findings show that very little research on what constitutes optimal functionality in a holistic perspective seen from the older adult's point of view exists. Furthermore, it is evident that no such concept exists today. Hence, the results presented in this review can be seen as a first step in exploring the concept of what constitutes optimal functionality in old age. These results will also serve as a foundation for further research in this domain to define the concept and to really reflect older adults' own opinions.

Among the identified self-related factors, mental aspects, such as psychological well-being, were recognized as the 
strongest predictor of well-being and life satisfaction. Therefore, these results confirm that maintained mental health is a major denominator in the concept of optimal functionality. The impact of mental health on the quality of life at old age has been further emphasized by the World Health Organization (WHO), which concludes that mental health is considered as valuable as physical health for experiencing a good quality of life. ${ }^{39}$

Furthermore, a positive mental attitude in conjunction with a problem-focused coping style predicts well-being and satisfaction with life. Thus, these factors are important in order to experience optimal functionality at old age. A prerequisite for healthy aging is to be able to adjust and compensate for losses and changes in life, as well as being able to cope with difficulties. ${ }^{40}$ This is strengthened by the selective optimization with the compensation model (SOCmodel) of successful aging. According to this model, the concept of successful aging refers to the resilience of people who succeed in achieving a positive balance between gains and losses during aging. ${ }^{41}$ This is, moreover, in line with the concept of proactive coping originally described by Aspinwall and Taylor in $1997 .{ }^{43}$ By foreseeing future problems and taking preventative actions, one might be able to maintain resources to achieve a positive balance between gains and losses. ${ }^{42,43}$ This is particularly important for older adults. The ability to cope with difficult life experiences is essential for them since many major life events, such as the death of friends and relatives or relocation, occur more often.

Moreover, the willingness to adjust appears to be important for promoting optimal functionality at an old age. The risk for disease and loss of function increases with age, which might lead to increased dependence and changed living conditions. According to our results, willingness to adjust to your living situation increases the perception of having a good life. This is supported by von Faber et al who recognize successful aging as a process of adaptation. ${ }^{44}$

Furthermore, maintaining good mental health appeared to be a strong predictor for life satisfaction. The absence of depressive symptoms in particular is of extra importance, since depression is a major issue among the older population. ${ }^{45}$ Reducing depression could promote successful aging as strongly as the reduction of physical disabilities. ${ }^{46}$ This clearly confirms the importance of mental health and psychiatry in promoting successful aging.

Physical activity, belonging to the theme body-related factors, was found to be a main contributor to optimal functionality. Being physically active and able to participate in activities promotes satisfaction and meaning in life. ${ }^{47-49}$ According to
Statistics Sweden, older adults exercise more today compared to previous generations, with the most common activities being gardening and going for walks. ${ }^{50}$ Effort should be put into helping old people maintain their functional ability, ${ }^{51}$ as it is important to be physically active in order to obtain optimal functionality. However, it is important to note that the choice of activity and its intensity seem to be of less importance.

Our results also show that having a large social network with a high quality of social relations is important for life satisfaction at old age. According to the WHO, favorable human contact is as important as physical health and therefore essential in order to experience a good life. ${ }^{39}$ The Senses Framework further supports the need for caring relationships in order for the older adult to experience a positive environment, particularly in a care setting. ${ }^{52}$ Moreover, the framework not only emphasizes the need for older adults to experience a helpful and understanding milieu with affectionate relationships, but also points out how important it is that relatives and staff generate an encouraging atmosphere in order to achieve optimal care of the older adult. ${ }^{52}$ To further point out the importance of caring relationships, the absence of social networks and social contact is strongly connected to loneliness. ${ }^{18,22}$

To maintain a process of healthy aging, the WHO further highlights the importance of being able to participate in social, cultural, and spiritual gatherings, something that several of the included articles in this review emphasize..$^{21,34-36,39}$

According to our results, a higher educational level and a stable economy predicts life satisfaction and subjective well-being at old age. Having a higher educational level often brings a more problem-focused coping style, which could serve as an explanation for higher life satisfaction in this group, considering our previously described results. Perceiving one's economy as good is likely to result in feelings of security. This is further supported by Buckley et al who show that factors, such as income and education, influence healthy aging. ${ }^{48} \mathrm{~A}$ stable economy could also contribute to better health care, a more comfortable life, and more opportunities for social interaction, thus giving a higher likelihood of experiencing optimal functionality.

\section{The need for a concept of optimal functionality}

In this article, we have pinpointed the areas of extra significance for the older adult to experience personal satisfaction according to the current literature, and laid the foundation for developing a concept of what constitutes optimal functionality from an older adult's point of view. 
The importance of taking older adults' perspectives into consideration is further emphasized by the progression of patient-centered care, which has been widely acknowledged, and today patient-reported outcome measures (PROMs) are under development. PROM consist of well-defined questionnaires completed by the patients themselves or via interviews. ${ }^{53,54}$ Hence, PROM is a tool striving to gather patients' views on their situation in the care setting. This is an important step in the health care system. However, our results demonstrate that the majority of factors found to be important for the older adult have been identified mainly through quantitative studies. It is therefore important to give voice to the older adult's own opinion regarding maintaining optimal functionality. This would generate a concept more in line with reality and reflect areas identified by the older adults themselves. A concept defining optimal functionality would further facilitate the identification of areas considered essential on an individual level to promote and maintain optimal functionality. In a broader perspective, such a concept could be applicable together with PROM to create a more accurate picture of the older adult, or be developed into an individual tool helping caregivers to identify those areas of extra significance for their patients. To our knowledge, this is the first review that has investigated optimal functionality from the older person's perspective. It is, however, important to note that our results show that there is a lack of qualitative studies and knowledge that take all the identified themes into consideration and look at them from the older adult's perspective. As a first step, it is therefore vital to manifest what constitutes optimal functionality from the older adult's perspective.

\section{Discussion of the methodology}

In this review, we have applied a scoping study approach, conducted by the methodological framework originally developed by Arksey and O'Malley in 2005. ${ }^{11}$ In addition, we have applied the advanced guidelines published in 2010 by Levac et al to further increase the accuracy of the methodology. ${ }^{55} \mathrm{To}$ capture the holistic perspective of optimal functionality, we set the key search term to (personal satisfaction) and (elderly OR older adults OR old age OR old persons). This term was identified through FGDs with older adults residing in senior living homes in the municipality of Örebro, Sweden. The FGDs only served to identify the key search term "personal satisfaction" and were not considered a part of the optional stage 6: consultation in the scoping review process. Thus, the key search term represents a factor essential to the older adults themselves in order to experience mental and physical wellbeing. It is therefore important to point out that the findings in this review are based on the search term (personal satisfaction) and not (optimal functionality). However, using the search term (personal satisfaction) and (elderly OR older adults OR old age OR old persons) retrieved articles with expressions such as "well-being", "life satisfaction", and "quality of life" in their title, which all are factors related to the individual's experience of fulfillment, thus emphasizing the relevance and accuracy of the selected search term. Moreover, it is important to note that the search term also generated articles focusing on the importance of physical activity. In fact, body-related factors were identified as one of the major themes. Thus, the search term was found to also cover the area of physical activity, which was the only area identified through the search term (optimal functionality) and (elderly OR older adults OR old age OR old persons). It should also be noted that the literature search retrieved articles in journals with a median impact factor of 1.678 (range $0-3.089$; the three journals where the impact factor was not available was set to 0 ), which falls within the normal range within this field. Thus, this further emphasizes the accuracy and eligibility of using the search term (personal satisfaction). The search term was entered into the electronic databases PubMed (US National Library of Medicine) and CINHAL, the major databases relevant to research within medical science and nursing science, respectively. Specific databases such as PyscINFO $^{\circledR}$ (American Psychological Association, Washington, DC, USA), devoted to peer-reviewed literature in behavioral sciences and mental health, were excluded in order to avoid a misallocation of articles belonging to a certain theme.

\section{Conclusion}

We conclude that there is a lack of knowledge and research in the current literature of what constitutes optimal functionality from the older adult's own perspective. Thus, we call for further qualitative studies raising the older adult's voice of what they find essential in order to live life as optimally as possible. The results outlined in this review identify three cornerstones (self-related factors, body-related factors, and external factors) of what constitutes optimal functionality at old age and compiles the present literature. Hence, our results can be seen as a first step towards defining the concept of optimal functionality in old age. However, it is vital that these findings are taken further and are evaluated through FGDs or interviews with older adults.

\section{Acknowledgments}

We acknowledge Bengt Björkstén, Carl Mårten Lindqvist, Gunnel Östlund, and Mandy Krahn for valuable input on 
the manuscript. This work was supported by the Knowledge foundation (grant ref: 20110225) and the Olle Engkvist Byggmästare foundation (grant approved for investigating the importance of nutrition and physical activity among older persons) as well as the Faculty of Medicine at Örebro University.

\section{Disclosure}

The authors declare no conflicts of interest in this work.

\section{References}

1. Kinsella K, Wan H. An Ageing World: 2008. Washington: US Government Printing Office; 2009. Available from: http://www.census.gov/ prod/2009pubs/p95-09-1.pdf. Accessed November 12, 2012.

2. Rosenstock IM, Strecher VJ, Becker MH. Social learning theory and the Health Belief Model. Health Educ Q. 1988;15(2):175-183.

3. Janz NK, Champion VL, Strecher VJ. The health belief model. In: Glanz K, Rimer BK, Rombouts FM, editors. Health Behavior and Health Education: Theory, Research, and Practice. 3rd ed. San Francisco: Jossey-Bass; 2002;2002.

4. Sayegh P, Knight BG. Cross-cultural differences in dementia: the Sociocultural Health Belief Model. Int Psychogeriatr. 2013;25(4): $517-530$.

5. Lilja M. Elderly Disabled Persons in the Home Setting: Aspects of Activities in Daily Life. Stockholm: Repro Print; 2000.

6. Larsson A, Haglund L, Hagberg JE. Doing everyday life - experiences of the oldest old. Scand J Occup Ther. 2009;16(2):99-109.

7. Ferrucci L, Guralnik JM, Simonsick E, Salive ME, Corti C, Langlois J. Progressive versus catastrophic disability: a longitudinal view of the disablement process. J Gerontol A Biol Sci Med Sci. 1996;51(3): M123-M130.

8. Heikkinen E. A life course approach research orientations and future challenges. Eur Rev Aging Phys Act. 2010;8(1):7-12.

9. Deary IJ, Corley J, Gow AJ, et al. Age-associated cognitive decline. $\mathrm{Br}$ Med Bull. 2009;92:135-152.

10. Salthouse TA. When does age-related cognitive decline begin? Neurobiol Aging. 2009;30(4):507-514.

11. Arksey H, O'Malley L. Scoping studies towards a methodological framework. Int J Soc Res Meth. 2005;8(1):19-32.

12. Rumrill PD, Fitzgerald SM, Merchant WR. Using scoping literature reviews as a means of understanding and interpreting existing literature. Work. 2010;35(3):399-404.

13. Barbour RS, Kitzinger J. Developing Focus Group Research: Politics, Theory and Practice. London: SAGE Publications; 1999.

14. Meléndez JC, Tomás JM, Oliver A, Navarro E. Psychological and physical dimensions explaining life satisfaction among the elderly: a structural model examination. Arch Gerontol Geriatr. 2009;48(3): 291-295.

15. Golden J, Conroy RM, Bruce I, et al. The spectrum of worry in the community-dwelling elderly. Aging Ment Health. 2011;15(8): 985-994.

16. Golden J, Conroy RM, Bruce I, et al. Loneliness, social support networks, mood and wellbeing in community-dwelling elderly. Int J Geriatr Psychiatry. 2009;24(7):694-700.

17. Berg AI, Hoffman L, Hassing LB, McClearn GE, Johansson B. What matters, and what matters most, for change in life satisfaction in the oldest-old? A study over 6 years among individuals 80+. Aging Ment Health. 2009;13(2):191-201.

18. Ní Mhaoláin AM, Gallagher D, O Connell H, et al. Subjective well-being amongst community-dwelling elders: what determines satisfaction with life? Findings from the Dublin Healthy Aging Study. Int Psychogeriatr. 2012;24(2):316-323.
19. Enkvist A, Ekström H, Elmståhl S. What factors affect life satisfaction (LS) among the oldest-old? Arch Gerontol Geriatr. 2012;54(1): 140-145.

20. Enkvist A, Ekström H, Elmståhl S. Life satisfaction (LS) and symptoms among the oldest-old: results from the longitudinal population study called Good Aging in Skåne (GÅS). Arch Gerontol Geriatr. 2012;54(1): 146-150.

21. Helvik AS, Engedal K, Krokstad S, Selbæk G. A comparison of life satisfaction in elderly medical inpatients and the elderly in a populationbased study: Nord-Trondelag Health Study 3. Scand J Public Health. 2011;39(4):337-344.

22. Borg C, Hallberg IR, Blomqvist K. Life satisfaction among older people $(65+)$ with reduced self-care capacity: the relationship to social, health and financial aspects. J Clin Nurs. 2006;15(5):607-618.

23. Chippendale T, Hardison M, Guttadauro T, Goodman D, Flint C, Billings S. Life satisfaction among elders in senior residences: a pilot study. Phys Occup Ther Geriatr. 2013;31(1):12-20.

24. Jones T, Rapport L, Hanks R, Lichtenberg P, Telmet K. Cognitive and psychosocial predictors of subjective well-being in urban older adults. Clin Neuropsychol. 2003;17(1):3-18.

25. Bishop AJ, Martin P, Poon L. Happiness and congruence in older adulthood: a structural model of life satisfaction. Aging Ment Health. 2006; 10(5):445-453.

26. McKinley K, Adler G. Quality of life in nursing homes: involving elders in policy making for their own care and life satisfaction. SOC Policy $J$. 2005;4(3-4):37-51.

27. Danhauer SC, Sorocco KH, Andrykowski MA. Accentuating the positive: recent "uplifts" reported by nursing home residents. Clin Gerontol. 2006;29(3):39-58.

28. Bergland A, Kirkevold M. Thriving in nursing homes in Norway: contributing aspects described by residents. Int J Nurs Stud. 2006; 43(6):681-691.

29. Andersson M, Hallberg IR, Edberg AK. Old people receiving municipal care, their experiences of what constitutes a good life in the last phase of life: a qualitative study. Int J Nurs Stud. 2008;45(6): $818-828$.

30. Good GA, LaGrow S, Alpass F. An age-cohort study of older adults with and without visual impairments: activity, independence, and life satisfaction. J Vis Impair Blind. 2008;102(9):517-527.

31. Stålbrand IS, Svensson T, Elmståhl S, et al. Subjective health and illness, coping and life satisfaction in an 80-year-old Swedish population-implications for mortality. Int J Behav Med. 2007;14(3): 173-180.

32. Raske M. Nursing home quality of life: study of an enabling garden. $J$ Gerontol Soc Work. 2010;53(4):336-351.

33. Sugiyama T, Thompson CW. Environmental support for outdoor activities and older people's quality of life. J Housing Elderly. 2005;19(1-2): $167-185$.

34. Berg AI, Hassing LB, McClearn GE, Johansson B. What matters for life satisfaction in the oldest-old? Aging Ment Health. 2006;10(3): 257-264.

35. Requena C, Martínez AM, Ortiz T. Vital satisfaction as a health indicator in elderly women. $J$ Women Aging. 2010;22(1):15-21.

36. McLaughlin D, Vagenas D, Pachana NA, Begum N, Dobson A. Gender differences in social network size and satisfaction in adults in their 70s. J Health Psychol. 2010;15(5):671-679.

37. Krause N. Longitudinal study of social support and meaning in life. Psychol Aging. 2007;22(3):456-469.

38. Nilsson G, Ohrvik J, Lonnberg I, Hedberg P. Low Psychological General Well-Being (PGWB) is associated with deteriorated 10-year survival in men but not in women among the elderly. Arch Gerontol Geriatr. 2011;52(2):167-171.

39. World Health Organization. Active Ageing: A Policy Framework. Geneva; World Health Organization; 2002. Available from: http:// whqlibdoc.who.int/hq/2002/WHO_NMH_NPH_02.8.PDF. Accessed November 12, 2012. 
40. Hansen-Kyle L. A concept analysis of healthy aging. Nurs Forum. 2005;40(2):45-57.

41. Baltes PB, Baltes MM. Psychological perspectives on aging: the model of selective optimization with compensation. In: Baltes PB, Baltes MM, editors. Successful Aging: Perspectives From the Behavioral Sciences. Cambridge: Cambridge University Press; 1993.

42. Aspinwall L. Where planning meets coping: proactive coping and the detection and management of potential stressors. In: Friedman SL, Scholnick EK, editors. The Developmental Psychology of Planning: Why, How, and When Do We Plan? Hillsdale: Psychology Press; 1997: 285-320.

43. Aspinwall LG, Taylor SE. A stitch in time: self-regulation and proactive coping. Psychol Bull. 1997;121(3):417-436.

44. von Faber M, Bootsma-van der Wiel A, van Exel E, et al. Successful aging in the oldest old: Who can be characterized as successfully aged? Arch Intern Med. 2001;161(22):2694-2700.

45. Bergdahl E, Gustavsson JM, Kallin K, et al. Depression among the oldest old: the Umeå 85+ study. Int Psychogeriatr. 2005;17(4):557-575.

46. Jeste DV, Savla GN, Thompson WK, et al. Association between older age and more successful aging: critical role of resilience and depression. Am J Psychiatry. 2013;170(2):188-196.

47. Peel NM, McClure RJ, Bartlett HP. Behavioral determinants of healthy aging. Am J Prev Med. 2005;28(3):298-304

48. Buckley NJ, Denton FT, Robb AL, Spencer BG. Healthy aging at older ages: are income and education important? Can J Aging. 2004; 23 Suppl 1:S155-S169.
49. Welsh D, Moore SL, Getzlaf BA. Meaning in life: the perspective of long-term care residents. Res Gerontol Nurs. 2012;5(3):185-194.

50. Statistics Sweden. [Living Conditions of the Elderly: Work, Economy, Health and Social Networks 1980-2003]. Örebro: SCB-Tryck; 2006. Available from: http://www.scb.se/statistik/_publikationer/ LE0101_1980I05_BR_LE112SA0601.pdf. Accessed November 12, 2012. Swedish.

51. Enkvist Å, Ekström H, Elmståhl S. Associations between functional ability and life satisfaction in the oldest old: results from the longitudinal population study Good Aging in Skåne. Clin Interv Aging. 2012;7: 313-320.

52. Nolan M, Davies S, Ryan T, Keady J. Relationship-centred care and the "Senses" framework. J Dement Care. 2008;16(1):26-28.

53. US Department of Health and Human Services FDA Center for Drug Evaluation and Research; US Department of Health and Human Services FDA Center for Biologics Evaluation and Research; US Department of Health and Human Services FDA Center for Devices and Radiological Health. Guidance for industry: patient-reported outcome measures: use in medical product development to support labeling claims: draft guidance. Health Qual Life Outcomes. 2006;4:79.

54. Daley KA. Person-centered care - what does it actually mean? Am Nurse. 2012;44(6):3.

55. Levac D, Colquhoun H, O’Brien KK. Scoping studies: advancing the methodology. Implement Sci. 2010;5:69.
Journal of Multidisciplinary Healthcare

\section{Publish your work in this journal}

The Journal of Multidisciplinary Healthcare is an international, peerreviewed open-access journal that aims to represent and publish research in healthcare areas delivered by practitioners of different disciplines. This includes studies and reviews conducted by multidisciplinary teams as well as research which evaluates the results or conduct of such teams or health-

\section{Dovepress}

care processes in general. The journal covers a wide range of areas and welcomes submission from practitioners at all levels, from all over the world. The manuscript management system is completely online and includes a very quick and fair peer-review system. Visit http://www.dovepress. com/testimonials.php to read real quotes from published authors. 